\title{
Comment on E-Cigarettes and Cardiovascular Risk: Beyond Science and Mysticism
}

\author{
Konstantinos E. Farsalinos, MD ${ }^{1}$ Giorgio Romagna, $\mathrm{MD}^{2}$ Jacques Le Houezec, $\mathrm{MD}^{3}$ \\ 1 Onassis Cardiac Surgery Center, Kallithea, Greece \\ ${ }^{2}$ Abich S.R.L. Biological and Chemical Toxicology Research Laboratory, \\ Verbania, Italy \\ Address for correspondence Konstantinos E. Farsalinos, MD, Onassis \\ Cardiac Surgery Center, Sygrou 356, Kallithea 17674, Greece \\ (e-mail: kfarsalinos@gmail.com).
}

3 Public Health and Tobacco dependence, Amzer Glas, Rennes, France

Semin Thromb Hemost 2014;40:517-518.

We read with particular interest the short review and opinion by Lippi et al about the potential cardiovascular risk of using e-cigarettes. ${ }^{1}$ It is our opinion that certain aspects presented in the article should be further addressed and clarified.

The potential risk for cardiovascular disease from e-cigarette use was mainly attributed by the authors to the effects of nicotine. However, several studies have shown that nicotine intake does not elevate cardiovascular risk. Longterm inhalation of nicotine was studied in animals; researchers did not observe any adverse effects on the lungs or development of atherosclerosis. ${ }^{2}$ A recent meta-analysis of controlled smoking cessation trials found that, although nicotine replacement therapies (NRTs) had a higher rate of any cardiovascular events, this was driven only by minor events such as heart palpitations; no elevation in the incidence of major adverse cardiovascular events (MACE) was found. ${ }^{3}$ Use of NRTs in high-risk individuals was similarly not associated with an elevated risk for MACE. ${ }^{3}$ A populationbased case-controlled study among 68 hospitals in the US found that the use of nicotine patches did not elevate the risk of first myocardial infarction. ${ }^{4}$ A meta-analysis of 34 randomized controlled trials showed that NRTs did not pose any elevated risk for myocardial infarction, stroke, palpitations, angina, arrhythmia, or hypertension compared with placebotreated patients. ${ }^{5}$ Even in patients with established cardiovascular disease, use of NRTs did not confer any additional risk compared with placebo and in fact their use was associated with reduced ischemia-related perfusion defects and elevated time to exercise-induced ischemia. ${ }^{6}$ Currently, there is consensus that nicotine has minimal effects in initiating and propagating atherosclerosis. ${ }^{7}$ Moreover, Lippi et al seem to have exaggerated on the toxicity of liquid nicotine present in e-cigarettes. Mayer recently showed that the traditionally proposed nicotine lethal dose of 30 to $60 \mathrm{mg}$ came from dubious experiments performed more than 150 years ago. ${ }^{8}$

published online May 6, 2014
Issue Theme An Update on the Thrombotic Microangiopathies Hemolytic Uremic Syndrome (HUS) and Thrombotic Thrombocytopenic Purpura (TTP); Guest Editors, Magdalena Riedl, MD, Dorothea Orth-Höller, MD, and Reinhard Würzner, MD, PhD.

By evaluating postmortem examinations, he defined that the lethal dose would be 500 to $1,000 \mathrm{mg}$ of acute intake, almost 20 times higher than currently assumed. In fact, this represents the total amount of nicotine that should be absorbed; knowing that voluminous vomiting is the first and main symptom of nicotine intoxication, it seems obvious that you need to ingest even higher amounts of nicotine to absorb lethal quantities. Further support for this came from a recent presentation of three cases of attempted suicide by ingesting nicotine liquid used for e-cigarettes; none of the cases were fatal, with one of them ingesting $1,500 \mathrm{mg}$ of nicotine. ${ }^{9}$

Smokeless tobacco is an alternative form of nicotine intake which does not involve combustion. Still it contains tobacco and several contaminants present in it. Snus is considered the least harmful type of smokeless tobacco due to the manufacturing process and selection of tobacco. A meta-analysis of epidemiological studies have found that, in nonsmokers, snus use results in mild elevation in fatal cardiovascular events while it had a paradoxical protective effect in nonfatal events compared with nonusers. ${ }^{10}$ In fact, the risk for fatal events was attributed to one study only, with four more studies showing no added risk. Another meta-analysis revealed that those who switched from cigarette to snus use reduced to half the risk for developing cardiovascular disease compared with smokers. ${ }^{11}$

Because of the absence of combustion and of cured tobacco, e-cigarettes are reasonably expected to significantly reduce the cardiovascular risk in smokers who switch. Obviously, there is no definite proof for that because long-term epidemiological studies cannot be performed until after several years of use by a significant part of the population. None can exclude the possibility of some residual risk, but this can only be evaluated by surveillance of use in the population level. Lack of long-term studies cannot be a valid argument to support that e-cigarettes should be banned or restricted, especially because we know that the levels of toxins emitted from e-cigarette use are minimal and

Copyright (c) 2014 by Thieme Medical Publishers, Inc., 333 Seventh Avenue, New York, NY 10001, USA. Tel: +1(212) 584-4662.
DOI http://dx.doi.org/ 10.1055/s-0034-1375702. ISSN 0094-6176. 
by orders of magnitude lower compared with tobacco cigarettes. $^{12,13}$ In some cases, exposure to toxic chemicals is similar to pharmaceutical NRTs. ${ }^{14}$ Nicotine intake is unlikely to significantly elevate harm; health organizations such as the Medicines and Healthcare Products Regulatory Agency and the National Institute for Health and Care Excellence in the United Kingdom are currently proposing the long-term use of nicotine (in the form of NRTs) as a substitute for smoking, acknowledging that a significant proportion of smokers are unable to quit with currently approved medications. ${ }^{15,16}$ Obviously, it would be preferable for smokers to quit either by themselves or by using approved methods. E-cigarettes are an option for the majority of smokers who cannot quit and currently available evidence suggests that they are expected to be less harmful than tobacco. $^{16}$

\section{Funding}

No funding was provided for this article.

\section{Conflict of Interest}

None of the authors have been funded by the tobacco industry. Konstantinos Farsalinos and Giorgio Romagna have performed and published studies for which the institutions were funded from e-cigarette companies. Jacques Le Houezec has received speaker honoraria and consultancy fees from Johnson \& Johnson, Novartis, Pfizer, and Pierre Fabre.

\section{References}

1 Lippi G, Favaloro EJ, Meschi T, Mattiuzzi C, Borghi L, Cervellin G. Ecigarettes and cardiovascular risk: beyond science and mysticism. Semin Thromb Hemost 2014;40(1):60-65

2 Waldum HL, Nilsen OG, Nilsen T, et al. Long-term effects of inhaled nicotine. Life Sci 1996;58(16):1339-1346

3 Mills EJ, Thorlund K, Eapen S, Wu P, Prochaska JJ. Cardiovascular events associated with smoking cessation pharmacotherapies: a network meta-analysis. Circulation 2014;129(1):28-41
4 Kimmel SE, Berlin JA, Miles C, Jaskowiak J, Carson JL, Strom BL. Risk of acute first myocardial infarction and use of nicotine patches in a general population. J Am Coll Cardiol 2001;37(5): 1297-1302

5 Greenland S, Satterfield MH, Lanes SF. A meta-analysis to assess the incidence of adverse effects associated with the transdermal nicotine patch. Drug Saf 1998;18(4):297-308

6 Mahmarian JJ, Moyé LA, Nasser GA, et al. Nicotine patch therapy in smoking cessation reduces the extent of exercise-induced myocardial ischemia. J Am Coll Cardiol 1997;30(1):125-130

7 Ambrose JA, Barua RS. The pathophysiology of cigarette smoking and cardiovascular disease: an update. J Am Coll Cardiol 2004; 43(10):1731-1737

8 Mayer B. How much nicotine kills a human? Tracing back the generally accepted lethal dose to dubious self-experiments in the nineteenth century. Arch Toxicol 2014;88(1):5-7

9 Christensen LB, Van't Veen T, Bang J. Three cases of attempted suicide by ingestion of nicotine liquid used in e-cigarettes. Clin Toxicol 2013;51(4):290

10 Lee PN. Epidemiological evidence relating snus to health-an updated review based on recent publications. Harm Reduct J 2013;10(1):36

11 Lee PN, Fry JS, Thornton AJ. Estimating the decline in excess risk of cerebrovascular disease following quitting smoking-a systematic review based on the negative exponential model. Regul Toxicol Pharmacol 2014;68(1):85-95

12 Cahn Z, Siegel M. Electronic cigarettes as a harm reduction strategy for tobacco control: a step forward or a repeat of past mistakes? J Public Health Policy 2011;32(1):16-31

13 Goniewicz ML, Knysak J, Gawron M, et al. Levels of selected carcinogens and toxicants in vapour from electronic cigarettes. Tob Control 2014;23(2):133-139

14 Farsalinos KE, Romagna G, Voudris V. Authors miss the opportunity to discuss important public health implications. J Chromatogr A 2013;1312:155-156

15 Medicines and Healthcare Products Regulatory Agency. Nicotine replacement therapy (NRT): New extended indication and consultation. 2010. Available at: http://www.mhra.gov.uk/Howweregulate/Medicines/Medicinesregulatorynews/CON065626. Accessed January 20, 2014

16 National Institute for Health and Care Excellence. Tobacco-harmreduction approaches to smoking: guidance. 2013. Available at: http://www.nice.org.uk/nicemedia/live/14178/63996/63996.pdf. Accessed January 20, 2014 